\title{
Sistem Pemantauan Sinyal Detak Jantung Pasien Menggunakan Protokol Zigbee Dan Arduino
}

\author{
Heart Tracker System Using Zigbee Protocol and Arduino
}

\author{
Tan Suryani Sollu', Alamsyah ${ }^{2}$, Muhammad Bachtiar ${ }^{3}$ \\ ${ }^{1,2,3}$ Program Studi Teknik Ekektro, Jurusan Teknik Elektro, Fakultas Teknik, Universitas \\ Tadulako
}

Jl. Soekarno Hatta KM.9, Tondo, Mantikulore, Kota Palu, 94118, 0451 - 422611

Email: ${ }^{1 *}$ tansuryani@yahoo.com, ${ }^{2}$ alamsyah.zakaria@untad.ac.id, ${ }^{3} \mathrm{~m} \_$bachtiar@yahoo.com

\begin{abstract}
Abstrak
Pemantauan sinyal detak jantung pasien bertujuan untuk meningkatkan keselamatan pasien dan mengurangi beban kerja dokter atau perawat dalam menangani kondisi pasien. Untuk melakukan pemantauan kesehatan jantung pasien diperlukan karakteristik kesehatan organ tubuh terutama organ jantung pada orang sehat atau orang sakit. Penelitian ini dirancang menggunakan protokol zigbee sebagai media transmisi dan modul arduino sebagai pengolah data, serta sensor ECG sebagai pendeteksi sinyal detak jantung yang ditempelkan pada tubuh pasien. Hasil penelitian menunjukkan bahwa pengambilan data yang dilakukan selama 15 detik pada pasien laki-laki dengan umur 25 tahun adalah $68 \mathrm{bpm}$. Pengambilan data sinyal detak jantung pasien menggunakan sensor nirkabel diperoleh nilai tegangan maksimum sebesar 3,25 volt dan nilai tegangan minimum sebesar 0 volt. Pengiriman 884 paket data yang dilakukan selama 15 menit melalui protokol zigbee mampu menerima data sebesar 4488 byte, throughput sebesar 2,39 Kbps dan delay rata-rata sebesar 0,24486 detik. Pengukuran jangkauan komunikasi untuk penempatan modul zigbee pada ruangan tertutup dan terbuka diperoleh kenaikan throughput dan delay pada setiap penambahan ketinggian, sedangkan packet loss terjadi penurunan pada setiap penambahan ketinggian.
\end{abstract}

Kata Kunci--pemantauan kesehatan, ECG, zigbee, arduino

\begin{abstract}
Monitoring the patient's heartbeat signal propose to improve patient safety and reduce the workload of physicians or nurses in dealing with the patient's condition. To perform the patient's heart health monitoring required characteristics of organ health, especially heart organ in healthy people or sick people. The research was designed using the Zigbee protocol as a transmission medium and an Arduino module as a data processor, as well as the ECG sensor as a detector of heartbeat signals attached to the patient's body. The results showed that the retrieval of data for 15 seconds in male patients with age 25 years was 68 bpm. Data collection of patient's heartbeat signal using a wireless sensor obtained a maximum voltage value of 3.25 volts and a minimum voltage value of 0 volts. The sending of 884 data packets which is conducted for 15 minutes via the Zigbee protocol is capable of receiving data of 4488 bytes, throughput of $2.39 \mathrm{Kbps}$ and an average delay of 0.24486 seconds. Measurement of communication scope for placement of Zigbee module in closed and open space obtained by throughput and delay increase at each addition to height, while packet loss decrease at every addition to height.
\end{abstract}

Keywords--health monitoring, ECG, zigbee, arduino 


\section{PENDAHULUAN}

Perkembangan teknologi dan sistem komunikasi jaringan nirkabel dalam bidang kesehatan telah menunjukkan perkembangan yang cukup pesat dan positif [1]. Salah satu teknologi jaringan berbasis nirkabel yang saat ini sedang dikembangkan, khususnya dalam bidang pemantauan kesehatan (vital sign) adalah sistem deteksi sinyal detak jantung [2] dan sitem pemantauan kesehatan manusia untuk mendeteksi adanya penyebaran bahan kimia beracun [3]. Penelitian yang dilakukan [4] tentang sistem aplikasi pemantauan proses rehabilitasi pasien berbasis jarak jauh, dan penelitian yang dilakukan [5] tentang sistem pemantauan vital sign berbasis wireless sensor network (WSN).

Penelitian sistem pemantauan sinyal detak jantung pasien dilakukan berdasarkan beberapa permasalahan, diantaranya: tenaga medis dalam melakukan pemeriksaan kondisi kesehatan jantung pasien jantung membutuhkan waktu yang cukup lama, karena seiring bertambahnya pasien yang membutuhkan pemeriksaan atau pengecekan pasien dan peralatan yang digunakan dalam memantau pemeriksaan kesehatan tubuh masih menggunakan media transmisi berupa kabel serial. Sedangkan untuk membuat desain arsitektur pengawasan kesehatan pasien, minimal terdapat tiga buah lapisan untuk menjalankan fungsinya [6].

Sistem pemantauan sinyal detak jantung pasien bertujuan memberikan kemudahan dalam memantau kondisi kesehatan pasien, efisiensi biaya operasional, mengurangi kesalahan diagnosa, dan mengubah sistem pemantauan kesehatan berbasis kabel menjadi sistem berbasis nirkabel (wireless), serta mendukung aplikasi praktek pelayanan kesehatan secara profesional yang melibatkan berbagai disiplin ilmu [7].

Konsep sistem pemantauan sinyal detak jantung pasien sangat menarik untuk diteliti, disebabkan jantung [8] merupakan pusat dari sistem peredaran darah manusia. Selanjutnya tingkat kematian tercatat $35 \%$ atau 1,8 juta penduduk Indonesia pada tahun 2014 disebabkan oleh penyakit jantung atau serangan jantung. Pemantauan kesehatan dapat mencakup: konsultasi, menjawab pertanyaan terkait riwayat medis atau gaya hidup seperti: merokok, minuman beralkohol dan berkaitan dengan yang menpengaruhi kesehatan [9].

Untuk menjalankan program ini, maka dibutuhkan suatu solusi untuk membantu tenaga medis dalam memonitor kondisi sinyal detak jantung pasien secara real time. Penelitian ini bertujuan merancang sebuah sistem pemantauan sinyal detak jantung pasien yang dapat mengatasi beban tenaga medis (dokter dan perawat), mengurangi kesalahan diagnosa jatung pasien, dan sebagai sistem pengambilan keputusan yang berbasis smart health.

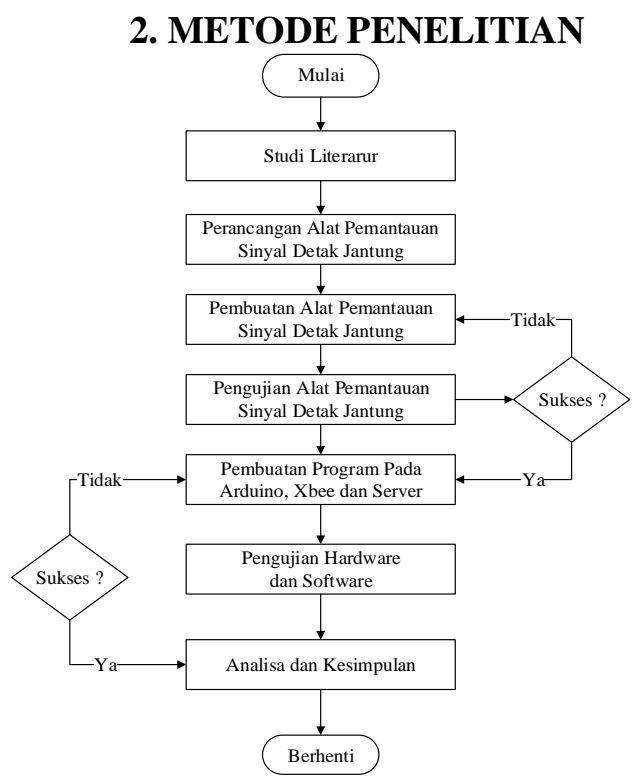

Gambar 1. Diagram alir penelitian 
Pada Gambar 1, menunjukkan proses atau tahapan penelitian yang dilakukan, diantaranya: tahapan studi literatur, perancangan alat dan pembuatan alat pemantauan sinyal detak jantung, pengujian perangkat keras, pembuatan perangkat lunak sistem pemantauan sinyak detak jantung, dan analisa hasil pengujian.

\subsection{Studi Literatur}

Tahapan ini adalah proses pencarian literatur yang sesuai dengan permasalahan yang akan diteliti, khususnya terkait dengan sistem pemantauan sinyal detak jantung. Target pada tahapan ini adalah mendukung hipotesa dalam perancangan sistem pemantauan sinyal detak jantung pasien berbasis nirkabel.

\subsection{Perancangan dan Pembuatan Alat}

Tahap perancangan dan pembuatan alat pemantauan sinyal detak jantung pasien menggunakan protokol zigbee dan arduino. Perancangan dan pembuatan alat ini terdiri dari perangkat keras berupa sensor ECG, modul arduino uno, modul zigbee, catu daya dan perangkat lunak berupa program aplikasi Integrated Developtment Enviroenment (IDE) untuk arduino, program aplikasi XCTU untuk modul zigbee, serta program aplikasi node.ijs untuk server. Perangkat output device yang dihasilkan adalah tampilan sinyal detak jantung pasien.

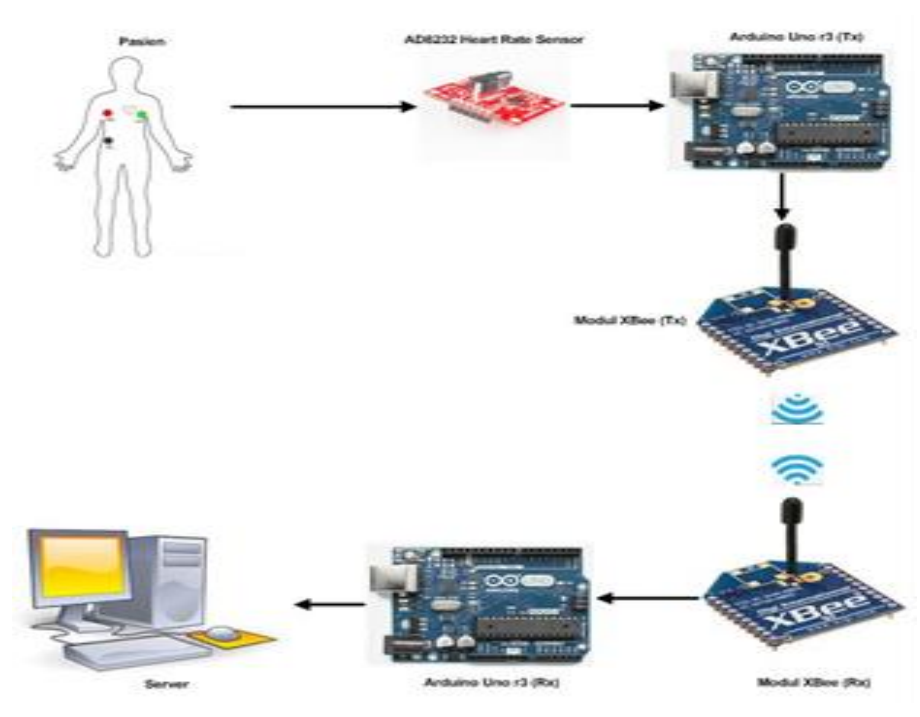

Gambar 2. Diagram blok hardware

Gambar 2, menunjukkan diagram blok sistem pemantauan sinyal detak jantung menggunakan protokol zigbee dan arduino.

Perancangan sistem pemantauan sinyal detak jantung pasien menggunakan protokol zigbee, dimana arduino uno telah terhubung dengan komputer sever menggunakan zigbee sebagai media transmisi berbasis wireless, dan data ECG pasien akan ditampilkan pada komputer server.

\section{a. Perancangan Hardware}

Perangkat keras yang digunakan terdiri dari sensor ECG, modul arduino uno, modul zigbee, komputer server dan catu daya sebagai penyedia sumber tegangan. 


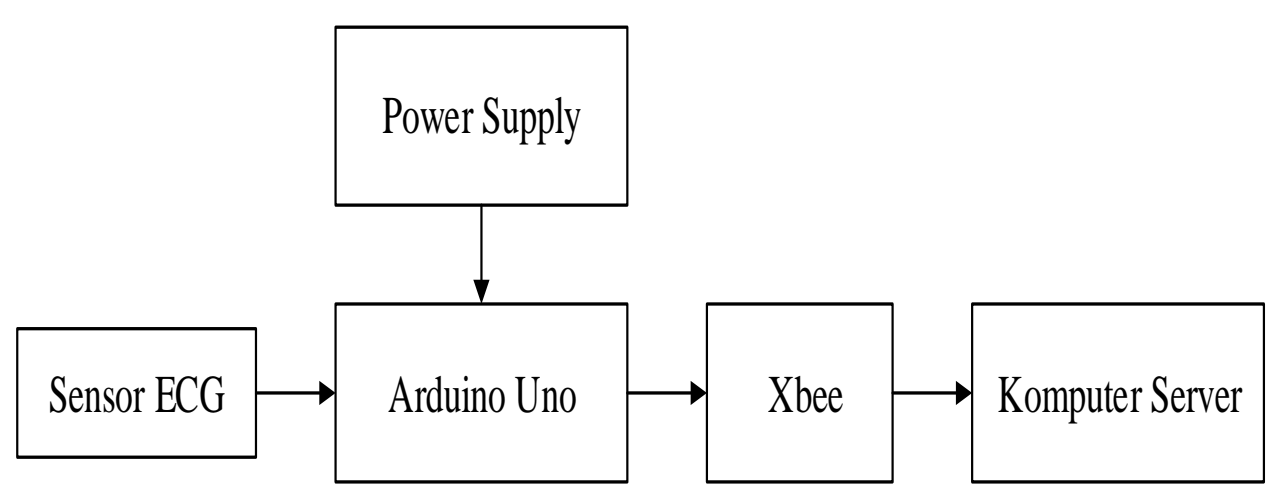

Gambar 3. Diagram blok hardware

Pada Gambar 3 menunjukkan skema rancangan blok hardware, dimana sinyal jantung merupakan sinyal analog yang sangat lemah, oleh karena itu sinyal jantung yang akan dihubungkan ke pin ekspansi analog pada sensorboard AD8232 terlebih dahulu akan diberi penguatan dan difilter. Untuk menghubungkan electrocardiograph ke node sensor (sensorboard AD8232), maka sinyal dikondisikan sesuai dengan spesifikasi AD8232. Konfigurasi sensorboard AD8232 dan arduino membentuk suatu node sensor. Node sensor bertugas melakukan sensing dan memberikan laporan pembacaan analog to digital converter (ADC) ke server melalui media transmisi dengan komunikasi menggunakan zigbee. Pada tahap selanjutnya, sistem akan diuji dengan memasukkan sinyal detak jantung dari hasil proses arduino melalui zigbee.

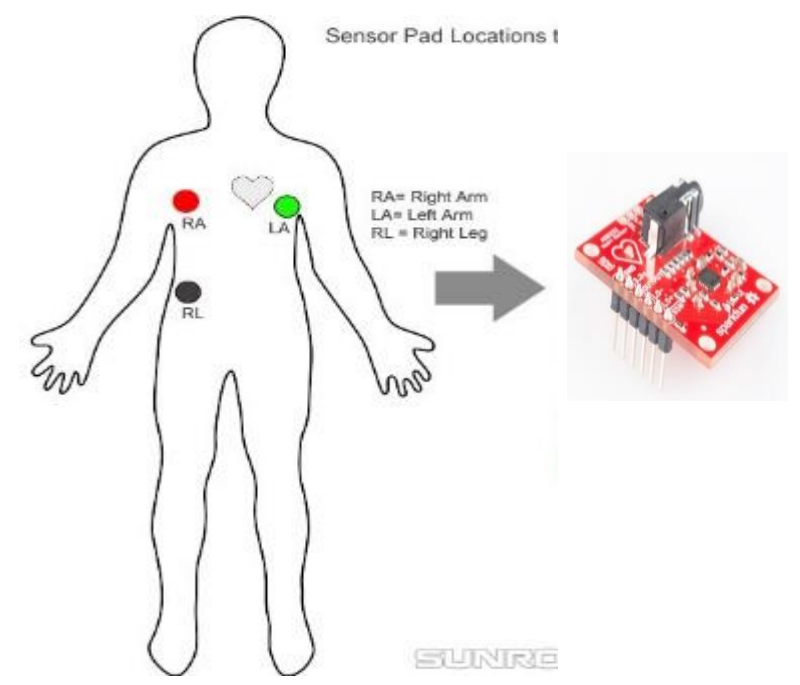

Gambar 4. Sensor ECG pada pasien

\section{b. Perancangan Software}

Perancangan perangkat lunak yang digunakan terdiri dari program aplikasi IDE untuk arduino dengan menggunakan bahasa pemograman $\mathrm{C}$, program aplikasi XCTU yang digunakan untuk melakukan set-up pada modul zigbee, serta program aplikasi node.ijs yang digunakan untuk menjalankan komputer server. Pada program XCTU yang dibuat pada sistem pemantauan sinyal detak jantung pasien menggunakan bahasa JavaScript. 


\section{HASIL DAN PEMBAHASAN}

Setelah melalui tahapan perancangan perangkat keras dan perangkat lunak sistem pemantauan sinyal detak jantung pasien, maka diperoleh hasil sebagai berikut.

\subsection{Validasi Pembacaan Sensor}

Hasil pengujian pada sensor board AD8232 dilakukan dengan melihat nilai tegangan yang tertera pada sensor board AD8232 dan melalui pembacaan pada volt meter. Pada sensor board AD8232 tertulis 3,3 volt dan pada pembacaan volt meter menunjukkan nilai 3,286 volt.

\subsection{Pengukuran Sinyal Tanpa Sensor Nirkabel}

Pada pengukuran pembacaan sinyal analog jantung dengan serial plotter yang ditransmisikan melalui media kabel dan wireless. Pengujian sinyal detak jantung yang berasal dari output sensorboard tidak ditransmisikan dengan menggunakan zigbee, tetapi hasil output dari sensor board AD8232 dilihat pada serial plotter arduino sebagai pembanding dengan sinyalsinyal jantung yang ditransmisikan dengan sensor. Pengambilan data dilakukan selama 15 detik pada laki-laki dengan usia 25 tahun menghasilkan periode sinyal jantung sebesar $68 \mathrm{bpm}$. Sinyal detak jantung yang didapatkan tidak mengalami delay rata-rata sebesar 0,245 detik. Namun masih memiliki noise akibat dari pengaruh sensifitas dari sensor elektroda yang melekat pada tubuh pasien.

Hasil pengukuran sinyal jantung pria menggunakan serial plotter dapat dilihat pada Gambar 5.

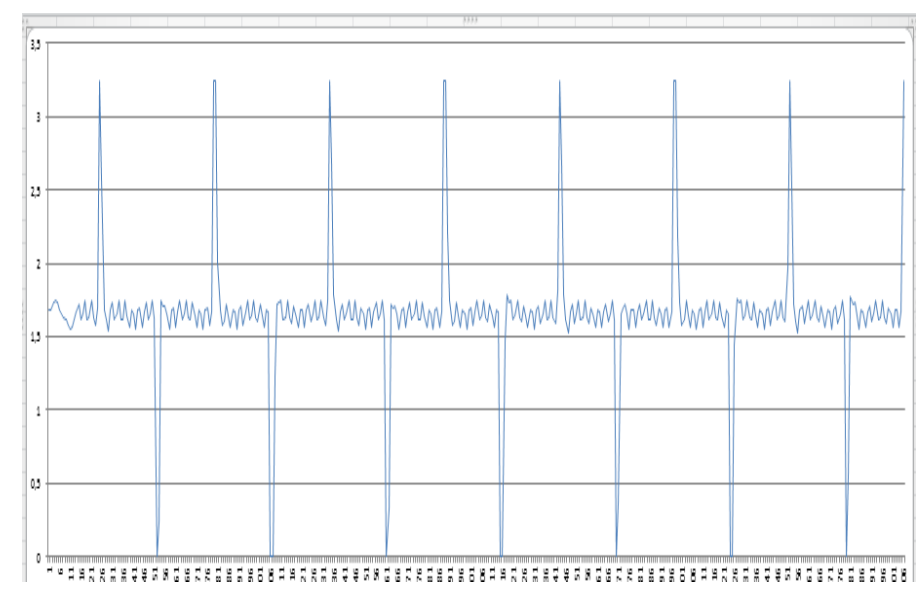

Gambar 5. Sinyal detak jantung dengan serial plotter

\subsection{Pengukuran Sinyal Dengan Sensor Nirkabel}

Pengujian sinyal detak jantung menggunakan modul zigbee yang dilakukan pada sinyal jantung laki-laki dengan umur 25 tahun didapatkan nilai tegangan maksimum sebesar 3,25 volt dan nilai tegangan minimum sebesar 0 volt. Sedangkan pengiriman 884 paket data yang dilakukan selama 15 menit melalui zigee mampu menerima data sebanyak 4488 byte, throughput sebesar $\quad 2,39 \mathrm{Kbps}$ dan delay rata-rata sebesar 0,24486 detik.

Hasil pengiriman paket data sinyal detak jantung yang diterima melalui zigbee dapat dilihat pada Gambar 6 dan 7. 


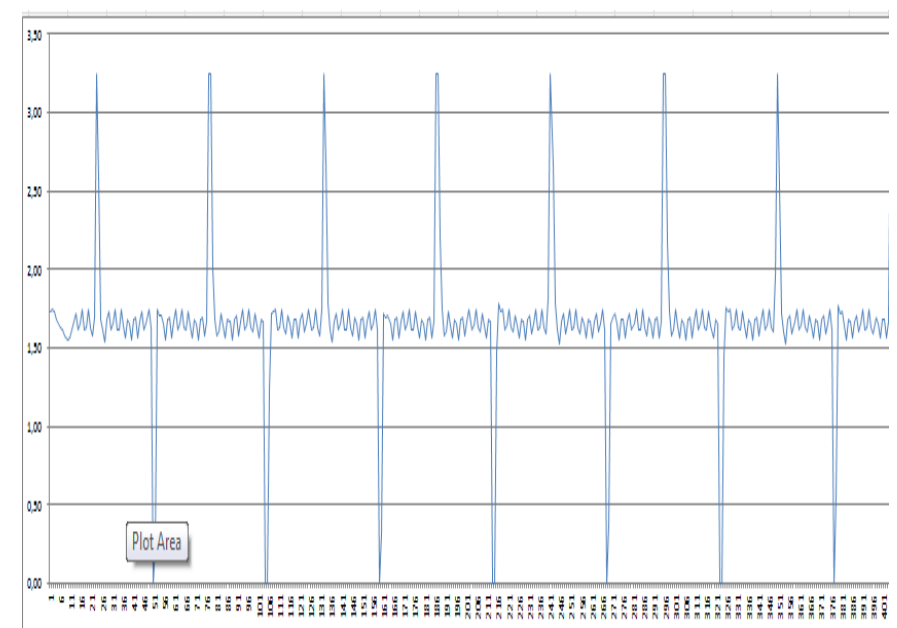

Gambar 6. Sinyal detak jantung dengan dengan media zigbee

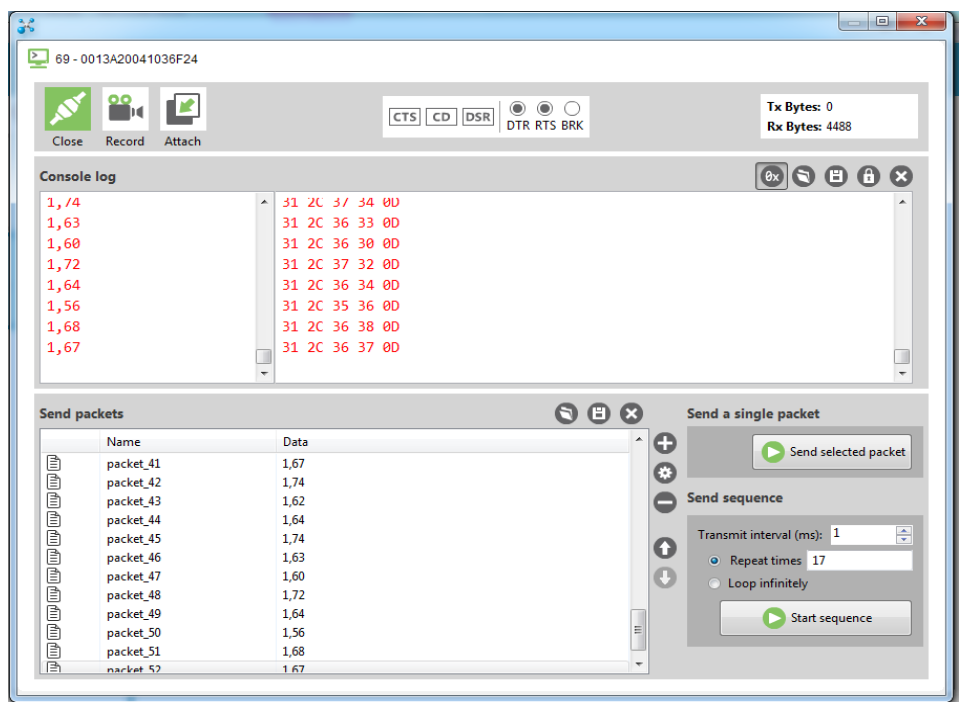

Gambar 7. Tampilan console zigbee

\subsection{Pengukuran Jangkauan Sinyal}

Pengukuran jangkauan sinyal komunikasi yang dilakukan dengan menempatkan modul zigbee berdasarkan pada ketinggian $50 \mathrm{~cm}$ sampai $200 \mathrm{~cm}$ untuk kondisi ruangan tertutup dan terbuka. Pada kondisi ruangan terbuka dengan jarak 38 meter dan pada kondisi ruangan tertutup pada jarak 23 meter, skenario penempatan sensor dilakukan pada ketinggian yang berbeda.

\section{a. Skenario Ruang Tertutup}

Tabel 1: Jangkauan sinyal komunikasi zigbee pada ruang tertutup

\begin{tabular}{|c|c|c|c|c|}
\hline $\begin{array}{c}\text { Ketinggian } \\
\text { zigbee } \\
(\mathrm{cm})\end{array}$ & $\begin{array}{c}\text { Tx } \\
\text { Data } \\
\text { (byte) }\end{array}$ & $\begin{array}{c}\text { Tx } \\
\text { Packet }\end{array}$ & $\begin{array}{c}\text { Rx } \\
\text { Packet }\end{array}$ & $\begin{array}{c}\text { Waktu } \\
(\mathrm{s})\end{array}$ \\
\hline 50 & 19280 & 249 & 239 & 60 \\
\hline 100 & 20080 & 251 & 251 & 60 \\
\hline 125 & 30880 & 386 & 386 & 60 \\
\hline 150 & 31200 & 390 & 390 & 60 \\
\hline 200 & 31440 & 393 & 393 & 60 \\
\hline
\end{tabular}


Pada Table 1, menunjukkan pengujian jangkauan sinyal komunikasi melalui zigbee pada skenario penempatan ruangan tertutup yang dilakukan pada ketinggian $50 \mathrm{~cm}-200 \mathrm{~cm}$ dengan data sebesar 80 byte yang dikirim secara terus menerus selama 60 detik.

Hasil pengujian yang telah dilakukan, diperoleh bahwa ketinggian kedua modul zigbee sangat berpengaruh pada nilai throughput yang dihasilkan, dimana nilai throughput semakin bertambah seiring dengan adanya penambahan ketinggian pada modul zigbee, seperti yang terlihat Gambar 8.

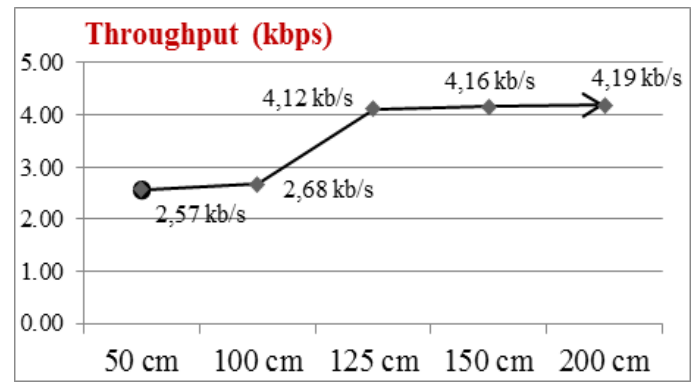

Gambar 8. Throughput kondisi indoor

Untuk hasil pengujian besarnya paket yang hilang (packet loss) pada saat kedua modul zigbee melakukan komunikasi pada ruang tertutup, menunjukkan bahwa nilai packet loss mengalami penurunan pada saat penempatan modul zigbee dilakukan penambahan ketinggian, selanjutnya nilai throughput akan konstan pada ketinggian $200 \mathrm{~cm}$ dengan nilai throughput yang dicapai sebesar 4,19 Kbps. Hasil pengukuran inidapat dilihat pada Gambar 9.

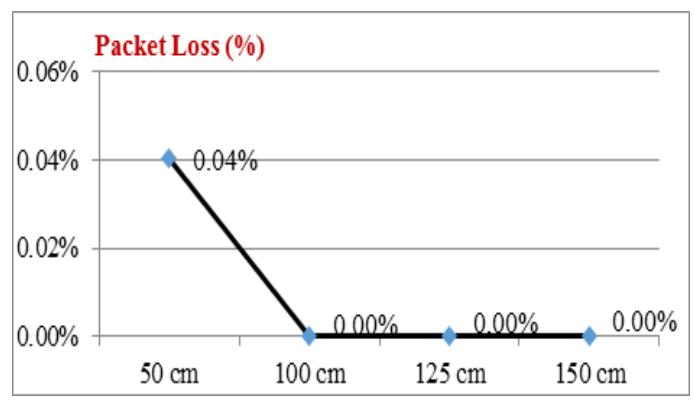

Gambar 9. Packet loss kondisi indoor

Sedangkan rata-rata delay yang dihasilkan dari hasil penempatan modul zigbee, menunjukkan bahwa rata-rata delay akan semakin meningkat dengan adanya penambahan ketinggian modul zigbee, selanjutnya rata-rata delay akan konstan pada penempatan modul zigbee untuk ketinggian $200 \mathrm{~cm}$ dengan hasil 6,55 detik. Hasil pengukuran ini, dapat dilihat pada Gambar 10.

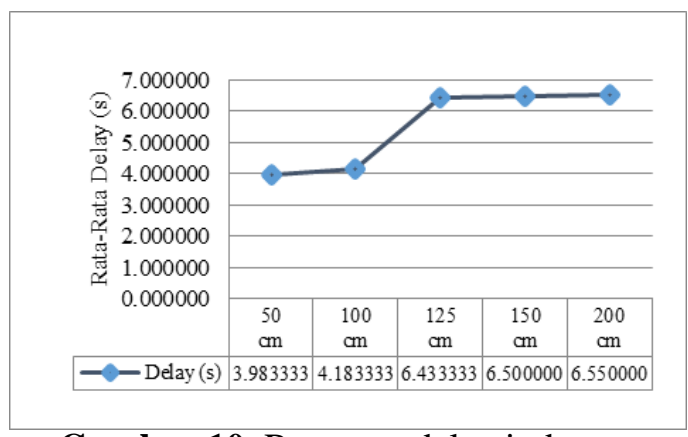

Gambar 10. Rata-rata delay indoor 


\section{a. Skenario Ruang Terbuka}

Pengujian sinyal komunikasi pada ruangan terbuka (Outdoor) dilakukan pengukuran dengan skenario menggunakan modul zigbee dengan mengirimkan 100 paket data secara terus menerus dihasilkan data sebesar 80 byte. Hasil pengujian menunjukkan bahwa komunikasi akan stabil pada ketinggian diatas $100 \mathrm{~cm}$. Hasil pengukuran secara lengkap dapat dilihat pada Tabel 2.

Tabel 2: Jangkauan sinyal komunikasi zigbee pada ruang terbuka

\begin{tabular}{|c|c|c|c|c|}
\hline $\begin{array}{c}\text { Ketinggian } \\
\text { zigbee } \\
(\mathrm{cm})\end{array}$ & $\begin{array}{c}\text { Tx } \\
\text { Data } \\
\text { (byte) }\end{array}$ & $\begin{array}{c}\text { Tx } \\
\text { Packet }\end{array}$ & $\begin{array}{c}\text { Rx } \\
\text { Packet }\end{array}$ & $\begin{array}{c}\text { Waktu } \\
(\mathrm{s})\end{array}$ \\
\hline $50 \mathrm{~cm}$ & 6160 & 100 & 77 & 15 \\
\hline $100 \mathrm{~cm}$ & 8000 & 100 & 100 & 15 \\
\hline $125 \mathrm{~cm}$ & 8000 & 100 & 100 & 15 \\
\hline $150 \mathrm{~cm}$ & 8000 & 100 & 100 & 15 \\
\hline $200 \mathrm{~cm}$ & 8000 & 100 & 100 & 15 \\
\hline
\end{tabular}

Pada Gambar 11, menunjukkan bahwa nilai throughput yang dihasilkan pada ketinggian $50 \mathrm{~cm}$ adalah 3,29 Kbps dan pada ketinggian $100 \mathrm{~cm}-200 \mathrm{~cm}$ adalah 4,27 Kbps. Hal ini menunjukkan bahwa nilai throughput semakin meningkat seiring dengan penambahan ketinggian modul zigbee.

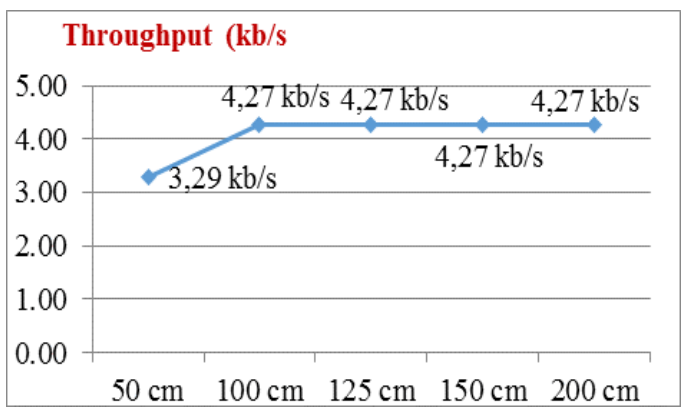

Gambar 11. Throughput outdoor

Pada Gambar 12, menunjukkan bahwa besarnya paket yang hilang akan semakin menurun atau sedikit pada saat penempatan modul zigbee dinaikkan ketinggiannya. Posisi packet loss mencapai $0 \%$ pada ketinggian $100 \mathrm{~cm}$.

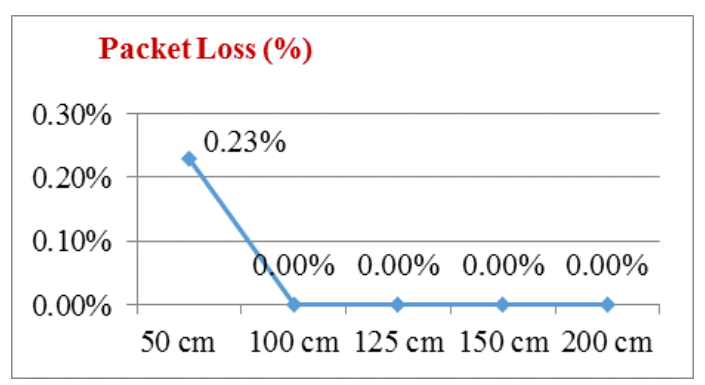

Gambar 12. Packet loss outdoor

Pada Gambar 13, menunjukkan bahwa nilai rata-rata delay akan meningkat, pada saat penempatan modul zigbee dinaikkan ketinggiannya. Nilai rata-rata delay akan tetap pada penempatan modul zigbee di ketinggian $100 \mathrm{~cm}$. 


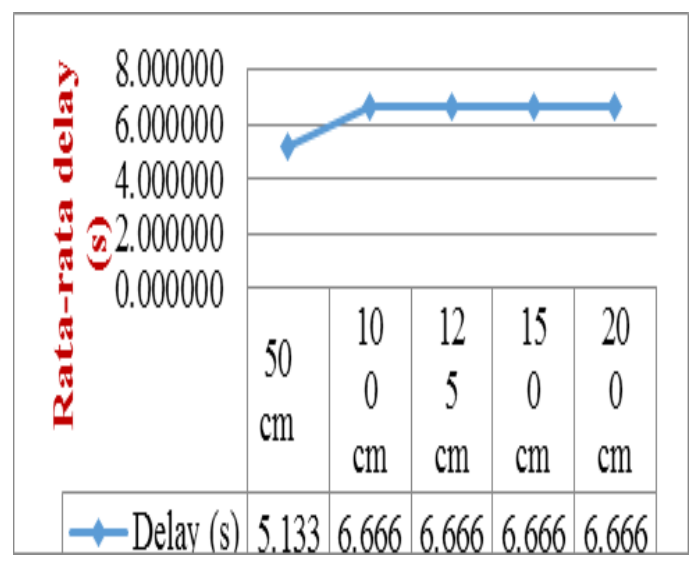

Gambar 13. Rata-rata delay indoor

\section{KESIMPULAN}

Pengujian data sensor sinyal detak jantung yang dilakukan dengan menggunakan serial plotter selama 15 detik pada pria dengan usia 25 tahun menghasilkan periode sinyal jantung sebesar $68 \mathrm{bpm}$. Sedangkan pengiriman jumlah paket sebanyak 884 paket menghasilkan data sebesar 4488 byte, , throughput 2,39 Kbps dan delay rata-rata 0,24486 detik.

Pengujian penempatan modul zigbee pada ruangan tertutup dan terbuka pada ketinggian $50 \mathrm{~cm}-200 \mathrm{~cm}$ untuk jarak 23 meter dan 38 meter dalam waktu 60 detik diperoleh kesimpulan bahwa penambahan ketinggian posisi modul zigbee akan menghasilkan nilai throughput dan delay, sedangkan nilai packet loss akan menurun pada saat penempatan modul dinaikkan ketinggiannya. Penempatan modul zigbee baik pada ruang tertutup maupun nilai throughput, delay dan packet loss akan stabil pada ketinggian $100 \mathrm{~cm}-200 \mathrm{~cm}$.

\section{SARAN}

Untuk pengembangan penelitian selanjutnya disarankan:

a. Perancangan sistem ini dapat dikembangkan dengan melakukan penambahan sensor, seperti: suhu tubuh, tekanan darah, dan nafas.

b. Sistem pemantauan sinyal detak jantung pasien dapat dikembangkan dengan menggunakan konsep machine learning, yaitu suatu konsep membangun sistem keputusan kondisi kesehatan jantung pasien apakah sehat atau tidak sehat.

c. Untuk menjaga agar power supply bisa bekerja dengan efektif, maka disarankan untuk merancang power supply secara otomatis yang terpasang pada modul sistem pemantauan kesehatan pasien.

\section{DAFTAR PUSTAKA}

[1] Shedge, S., 2010. Remote patient monitoring network cluster. Proceedings of the 2nd Makassar International Conference on Electrical Engineering and Informatics (MICEEI), Makassar Golden Hotel (MGH) Makassar, South Sulawesi, Indonesia, pp. 55-58

[2] Elyas, P., 2012. A $2.5 \mathrm{GHz}$ wireless ECG system for remotely monitoring heart pulses, "accepted for presentation at IEEE Antenna and Propagation Society (APS) Symposium/URSI/USNC Meeting. Chicago, IL, USA

[3] Kasem, S., 2007. Wireless Sensor Network: Technology, Protocol, and Applications, Wiley-interscience 
[4] P. Bonato, 2005. Advances in wearable technology and applications in physical medicine and rehabilitation. Journal of Neuro Engineering and Rehabilitation, Vol. 2

[5] Ilham, E. B., 2016. Multipoint Vital Sign Monitoring System Using Zigbee Wireless Sensor Network. Proceeding of Engineering : Vol.3, No.2 Agustus 2016| Page 1854

[6] Srijani, M., 2014. Patient Health Management System Using e-Health Monitoring Architecture," in IEEE International Advance Computing Conference

[7] Chetney, R., 2010. Home Care Technology and Telehealth The Future Is HERE. Home Healthcare Nurse, 21

[8] Evelyn, C. P., 2007. Anatomy and Physiology for Paramedics. Gramedia

[9] Safe Work Australia, 2013. Health Monitoring for Exposure to Hazardous Chemicals Guide for Workers. Australian Industry Group 